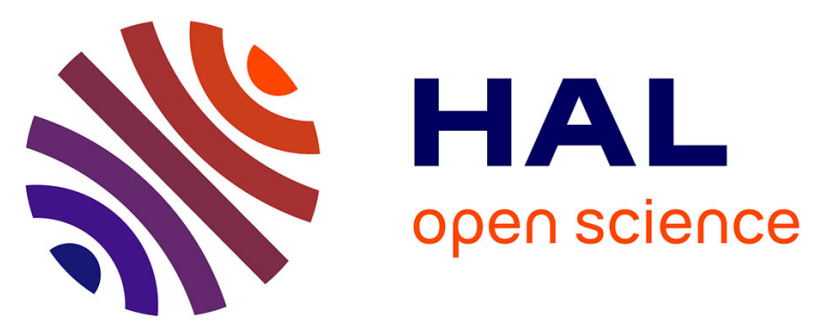

\title{
Atrophy mainly affects the limbic system and the deep grey matter at the first stage of multiple sclerosis
} Bertrand Audoin, W Zaaraoui, Francoise Reuter, Audrey Rico, Irina Malikova, Sylviane Confort-Gouny, Patrick J Cozzone, Jean Pelletier, Jean-Philippe Ranjeva

\section{To cite this version:}

Bertrand Audoin, W Zaaraoui, Francoise Reuter, Audrey Rico, Irina Malikova, et al.. Atrophy mainly affects the limbic system and the deep grey matter at the first stage of multiple sclerosis. Journal of Neurology, Neurosurgery and Psychiatry, 2010, 81 (6), pp.690. 10.1136/jnnp.2009.188748 . hal00557410

\section{HAL Id: hal-00557410 https://hal.science/hal-00557410}

Submitted on 19 Jan 2011

HAL is a multi-disciplinary open access archive for the deposit and dissemination of scientific research documents, whether they are published or not. The documents may come from teaching and research institutions in France or abroad, or from public or private research centers.
L'archive ouverte pluridisciplinaire HAL, est destinée au dépôt et à la diffusion de documents scientifiques de niveau recherche, publiés ou non, émanant des établissements d'enseignement et de recherche français ou étrangers, des laboratoires publics ou privés. 


\section{Atrophy mainly affects the limbic system and the deep grey matter at the first stage of multiple sclerosis}

Bertrand Audoin ${ }^{1,2}$, Wafaa Zaaraoui ${ }^{1}$, Françoise Reuter ${ }^{1,2}$, Audrey Rico ${ }^{1,2}$, Irina Malikova ${ }^{1,2}$, Sylviane Confort-Gouny ${ }^{1}$, Patrick J Cozzone ${ }^{1}$, Jean Pelletier ${ }^{1,2}$, Jean-Philippe Ranjeva ${ }^{1}$

${ }^{1}$ Centre de Résonance Magnétique Biologique et Médicale, UMR CNRS 6612, Faculté de Médecine, Université de la Méditerranée, 27 boulevard Jean Moulin, 13385 Marseille cedex 05, France

${ }^{2}$ Pôle de Neurosciences Cliniques, Centre Hospitalier Universitaire Timone, 260 boulevard St Pierre, 13005 Marseille, France

Total word count of the manuscript: 3206

Character count of the title: 89

Number of references: 37

Number of Table: 3

Number of Figure: 2

Corresponding author: Bertrand Audoin, MD PhD

CRMBM, UMR CNRS 6612 - Faculté de Médecine,

27 boulevard Jean Moulin

13386 Marseille, France.

Tel: (+33) 491384961

Fax : (+33) 491256529

Email: bertrand.audoin@ap-hm.fr

Keywords: multiple sclerosis, clinically isolated syndrome, magnetic resonance imaging, atrophy, voxel based morphometry

Competing Interest: None declared.

The Corresponding Author has the right to grant on behalf of all authors and does grant on behalf of all authors, an exclusive licence (or non-exclusive for government employees) on a worldwide basis to the BMJ Publishing Group Ltd, and its Licensees to permit this article (if 
accepted) to be published in JNNP and any other BMJPGL products and to exploit all subsidiary rights, as set out in our licence. 


\section{$\underline{\text { Abstract }}$}

The existence of grey matter (GM) atrophy right after the first clinical event suggestive of multiple sclerosis (MS) remains controversial. The aim of this study was therefore to establish whether regional GM atrophy is already present in the earliest stage of MS assessing regional GM atrophy in a large group of patients. Sixty two patients with a clinically isolated syndrome (CIS) were examined on a 1.5T MR imager within six months after their first clinical events. A group of thirty seven matched healthy control subjects were also included in the study. An optimized Voxel Based Morphometric (VBM) method customised for MS was applied on volumetric $\mathrm{T}_{1}$-weighted images. The functional status of patients was assessed using the Expanded Disability Status Scale (EDSS) and the Brief Repeatable Battery. VBM analysis ( $\mathrm{p}<0.005$, FWE corrected) on patients versus control subjects showed the presence of significant focal GM atrophy in patients involving the bilateral insula, the bilateral orbitofrontal cortices, the bilateral internal and inferior temporal regions, the posterior cingulate cortex, the bilateral thalami, the bilateral caudate nuclei, the bilateral lenticular nuclei, and the bilateral cerebellum. EDSS was slightly correlated (rho=-0.37 p=0.0027) with the atrophy of the right cerebellum. No correlations have been evidenced between the cognitive status of patients and the regional GM atrophy. The present study performed on a large group of CIS patients demonstrated that regional GM atrophy is present right after the first clinical event of multiple sclerosis and mainly affects the deep GM and the limbic system. 


\section{$\underline{\text { Introduction }}$}

Multiple sclerosis (MS) is an inflammatory disease affecting the central nervous system, which is frequently responsible for severe disability, mainly in the form of ambulatory deficits, which often develop after the disease has been evolving for several years. Grey Matter (GM) pathology in MS is now well recognized ${ }^{1}$ and could be relevant to the understanding of the clinico-radiological dissociation in patients with MS, where the focal demyelination in the white matter (WM) observed in conventional MRI cannot fully explain the clinical status (including cognitive impairment) ${ }^{1-3}$.

Various studies based on whole brain or whole GM analyses have shown that particularly high rates of atrophy sometimes occur during the first few years of the disease in patients with a clinical isolated syndrome (CIS) who undergo a subsequent conversion to clinically definite MS, but not in patients in whom this conversion does not occur ${ }^{4}$. Two recent studies using voxel based morphometry (VBM) methods on patients with CIS have yielded contradictory results. In the one study, which involved a relatively small sample of patients $(n=28)$, no regional GM atrophy was detected ${ }^{5}$, whereas the authors of the other study, which involved a larger group of patients $(n=41)$, reported the existence of significant regional GM atrophy, mainly located in the deep $\mathrm{GM}^{6}$.

The aim of the present study was therefore to assess the levels of regional GM atrophy present in a large group of MS patients at the earliest stage of the disease in order to provide evidence for or against the existence of early GM atrophy. Secondly, it was proposed to study the potential links between regional GM atrophy and clinical status of patients (including cognitive impairment). 


\section{$\underline{\text { Methods }}$}

\section{Subjects}

Sixty-two patients presenting with CIS and 37 healthy sex-age and educational level- matched control subjects were included in this study (Table 1). All the subjects (patients and controls) were right-handed (>70\% Olfield scale) native French speakers. Patients were recruited at the Department of Neurology (University Hospital of Marseille), based on the following criteria: 1) age between 18 and 45;2) occurrence of the first presumed inflammatory demyelinating event in the central nervous system involving either the optic nerve, the spinal cord, a brain hemisphere or the brainstem; 3) no previous history of neurological symptoms suggestive of demyelination; 4) no possible alternative diagnoses (lupus erythematosus, antiphospholipid antibody syndrome, Behcet disease, sarcoidosis, Lyme's disease, cerebral arteritis, brain lymphoma, etc.) 5) presence of oligoclonal bands on the CSF analysis; 6) presence of two or more lesions in the brain or spinal cord, detected at the initial MRI performed before inclusion. The last two criteria meant that only CIS patients fulfilling at least the dissemination in space criteria according to $\mathrm{McDonald}^{7}$ were recruited. According to these restricted criteria (especially the presence in all the patients of oligoclonal bands in the CSF and at least two T2 WM lesions on the brain MRI), the patients included in the present study presented high risk for developing MS.

Patients underwent a clinical examination during the first neurological episode. Another neurological examination was performed on the day of inclusion (the same day when MRI was performed). All the patients' disability levels were rated using the expanded disability status scale (EDSS) ${ }^{8}$ by the same neurologist (BA) on the day of inclusion. Neuropsychological tests were performed on the patients using the Brief Repeatable Battery (BRB) ${ }^{9}$ including the Selective Reminding Test, the Spatial Recall Test, the Symbol Digit Modalities Test, the Paced Auditory Serial Addition Task (3') and the Word list generation.

All the participants gave their informed consent to participating in this study, which was approved by the local Ethics Committee (Timone Hospital, Marseille, France).

\section{Brain MRI}

The subjects were examined on a 1.5T Magnetom Vision Plus MR Imager (Siemens, Erlangen, Germany). A sagittal three-dimensional MP-RAGE $\mathrm{T}_{1}$-weighted sequence (TE/TR 
$=4.7 \mathrm{~ms} / 9.7 \mathrm{~ms}$, flip angle $12^{\circ}, 128$ contiguous slices, matrix $=256^{2}$, isotropic voxel $1.25 \mathrm{~mm} \times 1.25 \mathrm{~mm} \times 1.25 \mathrm{~mm}$ ) and transverse fast double spin echo $\mathrm{T}_{2}$-weighted images $\left(\mathrm{TE}_{1} / \mathrm{TE}_{2} / \mathrm{TR}=15 \mathrm{msec} / 85 \mathrm{msec} / 2600 \mathrm{msec}, 44\right.$ contiguous slices, thickness $=3 \mathrm{~mm}$, flip angle $=90^{\circ}, \mathrm{FOV}=240 \mathrm{~mm}$, matrix $=256^{2}$ ) were acquired on all subjects.

\section{Image Processing}

\section{WM Lesion load}

WM lesions visible on T2-weighted images were contoured by the same neurologist (BA) using a semi-automated method (interactive thresholding technique written on the interactive data language (IDL) platform; Research System, Inc.).

WM lesion masks labelled as T1-WM lesion masks were identified by simultaneously viewing T1-weighted and T2-weighted images before contouring the lesions on the T1weighted images using the same semi-automated method (interactive thresholding technique written on the interactive data language (IDL) platform; Research System, Inc.).

\section{Optimized VBM}

The potential influence of the lesions on the results of the registration is a crucial point in VBM study performed in MS patients. This potential caveat is probably highly critical in patients with several years of disease evolution when the WM lesion load is important. Various methods have been proposed ${ }^{1011}$ to limit this effect. In the present study, to minimize this potential caveat, we used a modified version of the optimized VBM method ${ }^{12}$ customised for MS ${ }^{10}$, where WM lesions masks were applied to patients' scans at the end of images processing to remove any lesional tissue erroneously classified as grey matter. Figure 1 describes the analysis pipeline

Volumetric $\mathrm{T}_{1}$-weighted images were first normalized spatially (medium regularization, $7 \times 9 \times 7$ nonlinear basis functions) into the MNI space using the $\mathrm{T}_{1}$ anatomical template provided by the SPM2 program. Images were then re-sampled using an isotropic $1.5 \mathrm{~mm} \times 1.5 \mathrm{~mm} \times 1.5 \mathrm{~mm}$ voxel. The spatial normalization algorithm preserved the voxel intensities (concentrations) even when region volumes were stretched by warping. After smoothing the images with a $12-\mathrm{mm}$ Gaussian filter, a local $\mathrm{T}_{1}$ template was obtained by averaging the smoothed images obtained with each subject. 
Secondly, the 3D- $\mathrm{T}_{1}$-weighted volumes were normalized spatially into the MNI space using the local $T_{1}$ template previously obtained. Segmentation of these normalized 3-D $T_{1}$-weighted volumes was performed with each subject (SPM2). The resulting normalized GM fraction maps were smoothed using a $12 \mathrm{~mm}$ Gaussian filter and averaged across all controls to obtain the locally optimized GM template.

Thirdly, the 3D-T1 volumes obtained with each subject were directly segmented. The resulting GM fraction maps were normalized spatially using the locally optimized GM template. The transformation obtained for each spatial normalization was applied to the $3 \mathrm{D}$ $T_{1}$-weighted volumes and the WM $\mathrm{T}_{1}$ lesion masks of each subject. Then, the normalized $3 \mathrm{D}$ $\mathrm{T}_{1}$-weighted volumes were segmented and the normalized $\mathrm{T}_{1}$ lesion masks were subtracted from the normalized GM fraction maps to prevent misclassification of WM lesion

Lastly, a conservative threshold of 0.75 was applied to the resulting normalized GM fraction maps free of WM lesions before smoothing the images with a 12-mm FWHM Gaussian kernel ${ }^{12}$.

\section{Statistical mapping analysis}

Between-group comparisons (patients with CIS versus controls) were performed (two-sample t-test, $p<0.005, k=20$, FWE corrected, SPM2) on the smoothed GM fraction maps obtained using the optimized method to determine the location of clusters showing significant differences in the GM concentrations. Coordinates of significant clusters in the MNI space were transformed into Talairach coordinates using a nonlinear transformation to locate these clusters.

\section{$\underline{\text { Results }}$}

\section{Clinical and conventional MRI findings}

Patients' demographic and clinical characteristics of patients are given in Table 1. The median time between the clinical onset and the inclusion (the time when the MRI was performed) in the study was 4 months (0-6). Median age of the controls was 27 years (20-46), which did not differ significantly from that of the patients $(\mathrm{p}=0.94)$. A sub-population of 37 patients performed the neuropsychological testing. This sub-population did not differ significantly from the other patients in terms of sex, age, educational level, disease duration, T2LL or 
EDSS (Table 2). We also checked whether there existed any differences in terms of GM atrophy between the two groups of patients (those who underwent the neuropsychological tests and those who did not). These two groups were not found to differ in terms of the regional GM atrophy detected ( $\mathrm{p}<0.005$, FWE corrected). The patients' performances were compared with the performances previously recorded at our laboratory in a group of 52 healthy control subjects. The patients not differ from this control group in terms of sex, age or educational level (Table 2). Patients showed abnormally low performances in the Spatial Recall Test, the Symbol Digit Modalities Test, the Paced Auditory Serial Addition Task (3') and the Word list generation (Table 2).

Brain parenchyma fraction $(B P F)$ was not significantly decreased $(p=0.06)$ in patients $(\mathrm{BPF}=0.831 ; \mathrm{SD}=0.043)$ compared to controls $(\mathrm{BPF}=0.847 ; \mathrm{SD}=0.039) . \mathrm{GM}$ fraction $(\mathrm{GMF})$ was significantly decreased $(\mathrm{p}=0.01)$ in patients $(\mathrm{GMF}=0.50 ; \mathrm{SD}=0.045)$ compared to controls $(\mathrm{GMF}=0.52 ; \mathrm{SD}=0.046)$. WM fraction (WMF) was not decreased $(\mathrm{p}=0.94)$ in patients $(\mathrm{WMF}=0.33 ; \mathrm{SD}=0.025)$ compared to controls $(\mathrm{WMF}=0.33 ; \mathrm{SD}=0.021)$.

\section{Patterns of regional GM atrophy at the earliest stage of MS}

Results are summarized in Table 3 and Figure 2. At the FWE corrected statistical threshold level of $\mathrm{p}<0.005$, patients showed atrophy localized in the bilateral thalami, the bilateral caudate nuclei, the bilateral lenticular nuclei, the bilateral insula, the bilateral orbitofrontal cortices, the bilateral internal and inferior temporal regions, the posterior cingulate cortex and the bilateral cerebellum; whereas healthy controls showed no significant atrophy compared to patients.

\section{Correlations between conventional MRI data and regional cerebral atrophy}

The correlations have been assessed in the whole group of patients $(n=62)$. The degree of atrophy of the thalami was found to be significantly correlated with the T2LL (right thalamus: rho $=0.57 \mathrm{p}=0.001$; left thalamus: $r h o=0.48 \mathrm{p}=0.001)$. In the whole group of patients $(\mathrm{n}=62)$, local GM atrophy was not correlated with global GMF.

\section{Correlations between T2LL, physical and cognitive status}


EDSS scores assessed in all the patients $(n=62)$ correlated slightly with the T2LL (Rho $=0.26$, $\mathrm{p}=0.03$ ). In the sub-population of 37 patients with neuropsychological assessment, no correlations were found between T2LL and abnormal neuropsychological performances observed in patients.

\section{Correlations between regional GM atrophy, physical and cognitive status}

EDSS scores assessed in all the patients $(n=62)$ were found to be correlated with the degree of atrophy in the right cerebellum (Rho=-0.37 p=0.0027). In the sub-population of 37 patients having neuropsychological assessment, abnormal neuropsychological performances (Visuospatial memory (Short-term recall), Symbol Digit Modalities Test, Paced Auditory Serial Addition Task (3'), Word list generation) did not significantly correlate with the level of GM concentration in regions prone to atrophy 


\section{$\underline{\text { Discussion }}$}

The results of the present study on a large sample of patients with CIS provide evidence that regional GM atrophy is present in the first clinical stage of MS and that it mainly occurs in the deep GM and the limbic system.

\section{Pattern of local GM atrophy in patients in the earliest stage of MS}

Atrophy of the deep GM has been well documented in patients with relapsing remitting ${ }^{14} 15$ and primary progressive ${ }^{10}{ }^{13} \mathrm{MS}$. In a previous study on a relatively small group of patients $(\mathrm{n}=15)$ with early relapsing remitting MS (RRMS), no regional GM atrophy was detected at inclusion, whereas significant bilateral atrophy of the thalami was present two years later ${ }^{16}$. Apart form the thalamic atrophy, a subtle involvement of the thalamus may occur in the earliest stage of RRMS ${ }^{6}{ }^{17}$ : in a study on a small population of patients with CIS $(n=18)$, statistical mapping analysis applied to magnetization transfer ratio data showed significant tissue matrix disorganization of the deep GM relative to controls $(n=18){ }^{17}$. Recently, a VBM study performed in CIS demonstrated significant regional GM atrophy mainly located in the thalamus ${ }^{6}$. In the present study on a larger group of patients with CIS, GM atrophy was detected using the VBM method in the thalamus but also in the large majority of the deep GM structures.

Regional GM atrophy has been previously reported to occur in the temporal and the frontal cortices in patients with RRMS ${ }^{18}{ }^{19}$. In a study using a rather elegant approach to determine the cortical thickness, a local GM thinning was also observed in the cingulate gyrus, insula, and associative cortical regions, which correlated with the patients' neurological deficits and their T2 LL scores ${ }^{20}$. However, the method used in the latter study did not make it possible to explore the deep GM structures and no control data were used ${ }^{20}$. A recent MRI study on MS patients clearly established that the temporal lobe and the hippocampus were atrophic in patients with MS after several years of evolution ${ }^{21}$. Geurts et al ${ }^{22}$ also detected numerous inflammatory lesions in the hippocampus which may underlie tissue loss and GM atrophy evidenced by MRI.

The pathogenesis of early GM atrophy may involve different processes ${ }^{23}$. First, the axonal impairments resulting from WM lesions may induce distal GM lesions secondary to Wallerian degeneration ${ }^{24}$ or anterograde transynaptic damage ${ }^{25} 26$. In a large cohort of patients $(n=425)$ in the advanced stage of the disease, Charil et al. observed the existence of correlations 
between cortical thickness and the total lesion load and disability in the cingulate gyrus, insula, and associative cortical regions: these brain regions are strongly interconnected with other brain regions ${ }^{20}$. These authors suggested that interruption of WM tracts by MS plaques may contribute to the development of cortical atrophy. Similar observation have been evidenced recently by Henry and colleagues demonstrating a link between WM lesions located in the thalamo-cortical tract and the level of atrophy of the thalami ${ }^{27}$. This mechanism may explain the correlations observed in the present study between the $\mathrm{T}_{2} \mathrm{LL}$ and atrophy of the thalami, one of the most strongly connected GM regions. Another possibility is that a pathological process characterized by iron deposition may be involved in the inflammatory mechanism ${ }^{28}$. Significant correlations have been reported to exist between the number of T2 lesions and the abnormal iron deposition rates in the thalami ${ }^{29}$. These latter authors suggested that WM lesions may disrupt the axonal iron output, which leads to the accumulation of iron in the deep $\mathrm{GM}^{29}$.

Although the atrophy of the thalami was partly associated with the T2LL, no association with other atrophic GM regions have been evidenced suggesting that other factors may participate to regional atrophy. First, it is well known that the pathology of the WM is not restricted to the macroscopic WM lesions. Consequently, the mechanisms described above (Wallerian degeneration, anterograde transynaptic damage and disruption of the axonal iron output) may exist in the normal-appearing white matte inducing more diffuse GM atrophy. In addition the assessment of the potential association between the total lesion load and the regional GM concentration may be sub-optimal when considering the possibility of GM damage being mediated through WM tracts ${ }^{25}$. Diffusion tensor tractography may be relevant in future studies to better assess the potential link between lesions located in the WM tracts and remote GM pathology. Secondly, the limited association between WM lesions and GM atrophy may be related to the existence of another pathological process more restricted to the GM.

The authors of several studies have reported the occurrence of inflammatory lesions of the GM in MS. These GM inflammatory processes may consist of focal GM lesions and/or diffuse sub-pial inflammation ${ }^{30}$. The extension of diffuse inflammatory processes in the GM may be more pronounced in patients with progressive forms of the disease ${ }^{30}$. Up to now, no evidence has been available as to whether some GM structures may show preferential susceptibility to the GM inflammatory process occurring in MS. One hypothesis is that atrophy - the ultimate consequence of tissue injury - may start in the GM regions which are most sensitive to the diffuse inflammatory process, although this process may not be especially prominent in these regions. Another explanation for the pattern of distribution of 
the GM atrophy observed is that the GM inflammatory process may predominate in some regions, resulting in significant localized GM atrophy. However, to our knowledge, no data are available so far which shed light on the regional pattern of distribution of the GM inflammatory process in MS.

Another potential mechanism involved in GM atrophy may be represented by the pathology and/or loss of glial cells which represent $60 \%$ of the GM cell count in humans ${ }^{31}$.

\section{Relationships between regional GM atrophy and clinical status}

Since the population studied here consisted of patients presented with CIS, the residual EDSS recorded after the relapse was generally low (median 1, range 0-3.5), which meant that few correlations with regional GM atrophy were likely to occur. In addition, the limited association between brain regional GM atrophy and EDSS may be partly due to the characteristics of the EDSS scale particularly sensitive to spinal cord pathology not explored in the present study. Finally, compensatory processes known to occur from the very first stage of the disease onwards may limit the clinical impact of early regional GM loss. The only significant correlation observed, which was between the atrophy of the left cerebellum and the EDSS, was probably due to the fact that the cerebellum contributes importantly to movement control $^{32}$.

In the present study, the cognitive performances of patients with CIS were significantly impaired in tasks involving working memory, attention and speed of information processing. Previous studies have shown the existence of similar types of cognitive impairment in patients with CIS ${ }^{3334}$. Since all the cognitive abilities in question depend on widely distributed brain networks, these deficits may have resulted from connectivity disturbances secondary to WM injury ${ }^{35}$. The lack of correlation observed in the present study between cognitive impairment and regional GM atrophy suggests that the main pathological substrate of cognitive impairment in CIS patients is WM pathology. With the progression of the disease, the contribution of the GM injury probably increases, which would explaining the correlations found to exist between cognitive impairment and GM injury in patients after several years of disease evolution ${ }^{36}$. In addition, in a group of patients with RRMS and SPMS, Sanfilipo et al 37 observed that WM and GM injury had differential effects on the patients' cognitive performances. WM injury was found to be the best predictor of mental processing speed and working memory, whereas GM injury corresponded to verbal memory, euphoria, and disinhibition. In the present study on CIS patients, the fact that the cognitive impairments 
were restricted to mental processing speed and working memory may explain the lack of correlation observed between the regional GM volume and the cognitive deficits. The characteristics of the cognitive impairments may change slightly with the progression of the disease. In the very first stage, isolated processing speed and working memory deficits are directly related to the state of the WM. After several years, other cognitive abilities such as verbal memory are affected, probably due to the deterioration of the GM.

In addition, in view of the presence of the GM atrophy in the limbic and para-limbic regions, the main functional effect of the early GM pathology may be the emotional disturbances occurring at this stage in the disease. Since the patients' emotions were not assessed in the present study, it was not possible to test this hypothesis.

\section{Conclusion}

The present study performed on a large group of CIS patients with very low physical and cognitive disability, demonstrated highly significant regional GM atrophy in the deep GM and the limbic system. This study emphasized for an involvement of GM by MS pathological process from the onset of the disease.

\section{$\underline{\text { References }}$}

1. Geurts JJ, Barkhof F. Grey matter pathology in multiple sclerosis. Lancet Neurol 2008;7:841-851.

2. Bo L, Geurts JJ, van der Valk P, Polman C, Barkhof F. Lack of correlation between cortical demyelination and white matter pathologic changes in multiple sclerosis. Arch Neurol 2007;64:76-80.

3. Amato MP, Portaccio E, Goretti B, et al. Association of neocortical volume changes with cognitive deterioration in relapsing-remitting multiple sclerosis. Arch Neurol 2007;64:1157-1161.

4. Dalton CM, Chard DT, Davies GR, et al. Early development of multiple sclerosis is associated with progressive grey matter atrophy in patients presenting with clinically isolated syndromes. Brain 2004;127:1101-1107. 
5. Ceccarelli A, Rocca MA, Pagani E, et al. A voxel-based morphometry study of grey matter loss in MS patients with different clinical phenotypes. Neuroimage 2008;42:315-322.

6. Henry RG, Shieh M, Okuda DT, Evangelista A, Gorno-Tempini ML, Pelletier D. Regional grey matter atrophy in clinically isolated syndromes at presentation. J Neurol Neurosurg Psychiatry 2008;79:1236-1244.

7. McDonald WI, Compston A, Edan G, et al. Recommended diagnostic criteria for multiple sclerosis: guidelines from the International Panel on the diagnosis of multiple sclerosis. Ann Neurol 2001;50:121-127.

8. Kurtzke JF. Rating neurologic impairment in multiple sclerosis: an expanded disability status scale (EDSS). Neurology 1983;33:1444-1452.

9. Boringa JB, Lazeron $\mathrm{RH}$, Reuling IE, et al. The brief repeatable battery of neuropsychological tests: normative values allow application in multiple sclerosis clinical practice. Mult Scler 2001;7:263-267.

10. Khaleeli Z, Cercignani M, Audoin B, Ciccarelli O, Miller DH, Thompson AJ. Localized grey matter damage in early primary progressive multiple sclerosis contributes to disability. Neuroimage 2007;37:253-261.

11. Sdika M, Pelletier D. Nonrigid registration of multiple sclerosis brain images using lesion inpainting for morphometry or lesion mapping. Human Brain Mapping 2009; 30: 10601067.

12. Good CD, Johnsrude IS, Ashburner J, Henson RN, Friston KJ, Frackowiak RS. A voxel-based morphometric study of ageing in 465 normal adult human brains. Neuroimage 2001;14:21-36.

13. Sepulcre J, Sastre-Garriga J, Cercignani M, Ingle GT, Miller DH, Thompson AJ. Regional gray matter atrophy in early primary progressive multiple sclerosis: a voxel-based morphometry study. Arch Neurol 2006;63:1175-1180.

14. Ramasamy DP, Benedict RH, Cox JL, et al. Extent of cerebellum, subcortical and cortical atrophy in patients with MS: a case-control study. J Neurol Sci 2009;282:47-54.

15. Tao G, Datta S, He R, Nelson F, Wolinsky JS, Narayana PA. Deep gray matter atrophy in multiple sclerosis: a tensor based morphometry. J Neurol Sci 2009;282:39-46.

16. Audoin B, Davies GR, Finisku L, Chard DT, Thompson AJ, Miller DH. Localization of grey matter atrophy in early RRMS : A longitudinal study. J Neurol 2006;253:1495-1501.

17. Audoin B, Ranjeva JP, Au Duong MV, et al. Voxel-based analysis of MTR images: a method to locate gray matter abnormalities in patients at the earliest stage of multiple sclerosis. J Magn Reson Imaging 2004;20:765-771. 
18. Sailer M, Fischl B, Salat D, et al. Focal thinning of the cerebral cortex in multiple sclerosis. Brain 2003;126:1734-1744.

19. Battaglini M, Giorgio A, Stromillo ML, et al. Voxel-wise assessment of progression of regional brain atrophy in relapsing-remitting multiple sclerosis. J Neurol Sci 2009;282:55-60.

20. Charil A, Dagher A, Lerch JP, Zijdenbos AP, Worsley KJ, Evans AC. Focal cortical atrophy in multiple sclerosis: relation to lesion load and disability. Neuroimage 2007;34:509517.

21. Sicotte NL, Kern KC, Giesser BS, et al. Regional hippocampal atrophy in multiple sclerosis. Brain 2008;131:1134-1141.

22. Geurts JJ, Bo L, Roosendaal SD, et al. Extensive hippocampal demyelination in multiple sclerosis. J Neuropathol Exp Neurol 2007;66:819-827.

23. Chard D, Miller D. Grey matter pathology in clinically early multiple sclerosis: evidence from magnetic resonance imaging. J Neurol Sci 2009;282:5-11.

24. Evangelou N, Konz D, Esiri MM, Smith S, Palace J, Matthews PM. Regional axonal loss in the corpus callosum correlates with cerebral white matter lesion volume and distribution in multiple sclerosis. Brain 2000;123 ( Pt 9):1845-1849.

25. Audoin B, Fernando KT, Swanton JK, Thompson AJ, Plant GT, Miller DH. Selective magnetization transfer ratio decrease in the visual cortex following optic neuritis. Brain 2006;129:1031-1039.

26. Evangelou N, Konz D, Esiri MM, Smith S, Palace J, Matthews PM. Size-selective neuronal changes in the anterior optic pathways suggest a differential susceptibility to injury in multiple sclerosis. Brain 2001;124:1813-1820.

27. Henry RG, Shieh M, Amirbekian B, Chung S, Okuda DT, Pelletier D. Connecting white matter injury and thalamic atrophy in clinically isolated syndromes. J Neurol Sci 2009;282:61-66.

28. Bakshi R, Benedict RH, Bermel RA, et al. T2 hypointensity in the deep gray matter of patients with multiple sclerosis: a quantitative magnetic resonance imaging study. Arch Neurol 2002;59:62-68.

29. Ge Y, Jensen JH, Lu H, et al. Quantitative assessment of iron accumulation in the deep gray matter of multiple sclerosis by magnetic field correlation imaging. AJNR Am J Neuroradiol 2007;28:1639-1644.

30. Kutzelnigg A, Lucchinetti CF, Stadelmann C, et al. Cortical demyelination and diffuse white matter injury in multiple sclerosis. Brain 2005;128:2705-2712. 
31. Pelvig DP, Pakkenberg H, Stark AK, Pakkenberg B. Neocortical glial cell numbers in human brains. Neurobiol Aging 2008;29:1754-1762.

32. Ito M. Control of mental activities by internal models in the cerebellum. Nat Rev Neurosci 2008;9:304-313.

33. Achiron A, Barak Y. Cognitive impairment in probable multiple sclerosis. J Neurol Neurosurg Psychiatry 2003;74:443-446.

34. Feuillet L, Reuter F, Audoin B, et al. Early cognitive impairment in patients with clinically isolated syndrome suggestive of multiple sclerosis. Mult Scler 2007;13:124-127.

35. Audoin B, Guye M, Reuter F, et al. Structure of WM bundles constituting the working memory system in early multiple sclerosis: a quantitative DTI tractography study. Neuroimage 2007;36:1324-1330.

36. Amato MP, Bartolozzi ML, Zipoli V, et al. Neocortical volume decrease in relapsingremitting MS patients with mild cognitive impairment. Neurology 2004;63:89-93.

37. Sanfilipo MP, Benedict RH, Weinstock-Guttman B, Bakshi R. Gray and white matter brain atrophy and neuropsychological impairment in multiple sclerosis. Neurology 2006;66:685-692.

\section{Acknowledgments}

This research was supported by the CNRS, the Institut Universitaire de France, BayerSchering France, and The French 'Association pour la Recherche sur la Sclérose en Plaques' (ARSEP). There is no any financial interest related to this study from any of the authors. 


\begin{tabular}{|l|c|c|c|}
\hline & $\begin{array}{c}\text { Whole group } \\
\text { of Patients } \\
(\mathrm{n}=62)\end{array}$ & $\begin{array}{c}\text { Patients with } \\
\text { neuropsychological } \\
\text { assessment (n=37) }\end{array}$ & $\begin{array}{c}\text { Mann } \\
\text { Whitney } \\
\text { U test* }\end{array}$ \\
\hline Age (median) & $29(20-46)$ & $29.5(21-45)$ & NS (0.94) \\
\hline $\begin{array}{l}\text { Time from the } \\
\text { clinical onset } \\
\text { (month, } \\
\text { median) }\end{array}$ & $4(0-6)$ & $4(1-6)$ & NS (0.46) \\
\hline $\begin{array}{l}\text { T2LL (cm3, } \\
\text { median) }\end{array}$ & $2.2(0.1-111)$ & $2.5(0.1-61)$ & NS (0.7) \\
\hline $\begin{array}{l}\text { EDSS } \\
\text { (median) }\end{array}$ & $1(0-3.5)$ & $1(0-2)$ & NS (0.64) \\
\hline $\begin{array}{l}\text { Type of } \\
\text { symptoms: }\end{array}$ & $24(38.7 \%)$ & $16(44.4 \%)$ & \\
\hline Spinal cord & $16(25.8 \%)$ & $11(30.5 \%)$ & \\
\hline Brainstem & $15(24.2 \%)$ & $5(13,9 \%)$ & \\
\hline Optic nerve & $7(11.3 \%)$ & $4(11.1 \%)$ & \\
\hline Hemispheric & & & \\
\hline Table 1. Demographic & & \\
\hline
\end{tabular}

Table 1. Demographic and clinical characteristics of CIS patients.

* statistical comparison between patients with neuropsychological assessment and the whole group of patients 


\begin{tabular}{|c|c|c|c|}
\hline & $\begin{array}{l}\text { CIS Patients with } \\
\text { neuropsychological } \\
\text { assessment }(n=37)\end{array}$ & Controls $(\mathrm{n}=54)$ & $\mathrm{P}(\mathrm{t}-$ Test $)$ \\
\hline $\begin{array}{l}\text { Age (years, } \\
\text { mean (SD)) }\end{array}$ & $29(7)$ & $28(8)$ & $\mathrm{NS}(\mathrm{p}=0.9)$ \\
\hline $\begin{array}{l}\text { Educational } \\
\text { Level (years, } \\
\text { mean (SD)) }\end{array}$ & $13(3)$ & $13(3)$ & $\mathrm{NS}(\mathrm{p}=0.8)$ \\
\hline $\begin{array}{l}\text { Selective } \\
\text { Reminding Test }\end{array}$ & & & \\
\hline $\begin{array}{l}\text { Long Term } \\
\text { Storage }\end{array}$ & $58(10)$ & $60(7)$ & $\mathrm{NS}(\mathrm{p}=0.2)$ \\
\hline $\begin{array}{l}\text { Consistent } \\
\text { Long Term } \\
\text { Retrieval }\end{array}$ & $54(12)$ & $55(10)$ & $\mathrm{NS}(\mathrm{p}=0.5)$ \\
\hline $\begin{array}{l}\text { Delayed } \\
\text { Recall }\end{array}$ & $11(1.4)$ & $12(0.8)$ & $\mathrm{NS}(\mathrm{p}=0.08)$ \\
\hline $\begin{array}{l}\text { Visuo-spatial } \\
\text { memory }\end{array}$ & & & \\
\hline $\begin{array}{l}\text { Short-term } \\
\text { recall }\end{array}$ & $20(5)$ & $23(5)$ & 0.02 \\
\hline $\begin{array}{l}\text { Long-term } \\
\text { recall }\end{array}$ & $7.4(2.5)$ & $8(2)$ & $\mathrm{NS}(\mathrm{p}=0.12)$ \\
\hline $\begin{array}{l}\text { Symbol Digit } \\
\text { Modalities Test }\end{array}$ & $52(10)$ & $59(9)$ & 0.0008 \\
\hline $\begin{array}{l}\text { Paced Auditory } \\
\text { Serial Addition } \\
\text { Task (3') }\end{array}$ & $40(10)$ & $48(8)$ & $<0.0001$ \\
\hline $\begin{array}{l}\text { Word list } \\
\text { generation }\end{array}$ & $30(9)$ & $36(10)$ & 0.001 \\
\hline
\end{tabular}

Table 2. Regions showing significant GM atrophy in CIS patients $(\mathrm{n}=62)$ compared to controls $(n=37)(p<0.005$, FWE corrected). 


\begin{tabular}{|c|c|c|c|c|c|}
\hline Regions & Side & $\begin{array}{l}\text { Brodmann } \\
\text { areas }\end{array}$ & $\begin{array}{l}\text { Talairach } \\
\text { coordinates }\end{array}$ & $\mathbf{T}$ & $\begin{array}{l}\text { Number } \\
\text { of voxels }\end{array}$ \\
\hline \multirow[t]{2}{*}{ Caudate } & Right & $N A$ & -16205 & 10.6 & \multirow[t]{9}{*}{4848} \\
\hline & Left & $N A$ & 14183 & 9.73 & \\
\hline \multirow[t]{2}{*}{ Lenticular nucleus } & Right & $N A$ & -2665 & 6.6 & \\
\hline & Left & $N A$ & 2643 & 6.1 & \\
\hline \multirow[t]{2}{*}{ Thalamus } & Right & $N A$ & $-14-3111$ & 7.7 & \\
\hline & Left & $N A$ & $12-1916$ & 7.3 & \\
\hline Amygdala & Right & $N A$ & $24-6-13$ & 10.12 & \\
\hline \multirow[t]{2}{*}{ Insula } & Right & $N A$ & -3627 & 5.6 & \\
\hline & Left & $N A$ & 42107 & 5.7 & \\
\hline \multirow[t]{2}{*}{ Cerebellum } & Right & $N A$ & $-40-78-15$ & 7 & \multirow[t]{2}{*}{1620} \\
\hline & Left & $N A$ & $22-88-16$ & 6.7 & \\
\hline \multirow[t]{7}{*}{ Orbito-frontal cortex } & \multirow[t]{4}{*}{ Left } & \multirow[t]{2}{*}{$B A 47$} & $48 \quad 38-10$ & 7.3 & \multirow[t]{4}{*}{423} \\
\hline & & & $289-17$ & 7.3 & \\
\hline & & \multirow[t]{2}{*}{$B A 11$} & $25 \quad 50-16$ & 5.7 & \\
\hline & & & $18 \quad 38 \quad-22$ & 6.4 & \\
\hline & \multirow[t]{3}{*}{ Right } & $B A 47$ & $-269-17$ & 7.7 & \multirow[t]{3}{*}{297} \\
\hline & & $B A 11$ & $\begin{array}{lll}-32 & 44 & -12 \\
\end{array}$ & 7.4 & \\
\hline & & & $\begin{array}{lll}-12 & 40 & -20\end{array}$ & 7 & \\
\hline \multirow[t]{3}{*}{ Hippocampus } & \multirow[t]{2}{*}{ Right } & \multirow[t]{2}{*}{$N A$} & $-28-18-11$ & 7.5 & \multirow[t]{2}{*}{287} \\
\hline & & & $-32-29-5$ & 7 & \\
\hline & Left & $N A$ & $32-30-5$ & 5.3 & 86 \\
\hline $\begin{array}{l}\text { Posterior cingulate } \\
\text { cortex }\end{array}$ & & $B A 31$ & $0 \begin{array}{lll}0 & -34 & 27\end{array}$ & 7.1 & 71 \\
\hline \multirow{4}{*}{$\begin{array}{l}\text { Inferior temporal } \\
\text { cortex }\end{array}$} & \multirow[t]{2}{*}{ Right } & \multirow[t]{2}{*}{ BA 20} & $-36-6 \quad-38$ & 7.5 & \multirow[t]{2}{*}{38} \\
\hline & & & $-57-21-24$ & 6.2 & \\
\hline & \multirow[t]{2}{*}{ Left } & BA 37 & $\begin{array}{lll}57 & -47 & -9\end{array}$ & 5.9 & \multirow[t]{2}{*}{22} \\
\hline & & BA 20 & $38-4-40$ & 5.4 & \\
\hline
\end{tabular}

Table 3. Neuropsychological tests used and results for healthy controls and CIS patients 
Figure 1. Analysis pipeline of the VBM procedure

Figure 2. Regions showing significant GM atrophy in CIS patients $(n=62)$ compared to controls $(n=37)(p<0.005$, FWE corrected). GM atrophy was localized in the bilateral thalami, the bilateral caudate nuclei, the bilateral lenticular nuclei, the bilateral insula, the bilateral orbitofrontal cortices, the bilateral internal temporal regions, the posterior cingulate cortex and the bilateral cerebellum. 


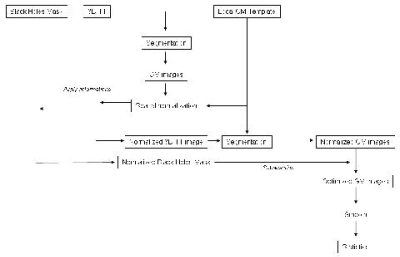




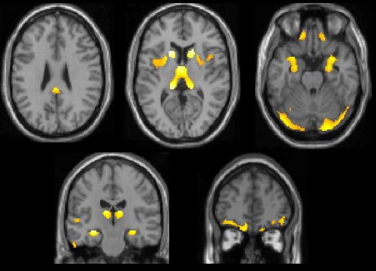

